\title{
Las medidas extraordinarias y los decretos de urgencia en el modelo constitucional peruano
}

Ricardo Herrera VásQueZ

\section{Introducción}

Uno de los principales problemas surgidos en la práctica constitucional, desde la perspectiva del equilibrio en la división de funciones de los poderes estatales, consiste en el empleo indiscriminado y frecuentemente inconstitucional de las medidas extraordinarias previstas en las cartas magnas vigentes durante el actual proceso democrático, como potestad normativa del Poder Ejecutivo.

Antes del célebre 5 de abril de 1992, ya se habían emitido más de dos mil quinientas medidas extraordinarias para regular todo tipo de materias, desbordando el marco de lo económico y financiero de manera preocupantemente frecuente. Por estas consideraciones, las medidas extraordinarias constituyen un tema de inocultable importancia y actualidad. Ya ha sido tratado intensamente por la doctrina nacional y extranjera de manera que el presente trabajo pretende, básicamente, sistematizar las opiniones a las que tenemos acceso en nuestro reducido mercado bibliográfico, aventurando algunas ideas particulares.

En primer lugar, abordaremos los antecedentes normativos de la institución en referencia, respecto del Derecho comparado y nacional. Acto seguido, pasaremos a analizar su regulación en la Constitución de 1979, a partir del debate preliminar en la Asamblea Constituyente. Trataremos también dos temas conexos: las medidas previstas en el artículo $132^{\circ}$ y la Ley No. 25397 -de control parlamentario de los actos normativos del Presidente de la República-. Por último, evaluaremos su regulación en la actual Carta Magna. 


\section{Antecedentes normativos}

\section{En el Derecho comparado}

El primer texto constitucional que abordó sistemáticamente el tema de los decretos de urgencia, fue la Carta Magna de Austria de 1920 (elaborada con la participación de Hans Kelsen). En ella se contemplaba la figura de los «decretos transitorios de modificación de leyes», como potestad legislativa del Poder Ejecutivo (Art. $18^{\circ}$ ). En cuanto a los requisitos que debían cumplir estas normas para ser válidas destacaban su urgente necesidad para evitar un daño público irreparable y la suspensión de funciones del Consejo Federal (Senado) (Planas Silva, 1993: 134).

Además, estas disposiciones eran estrictamente temporales, debían ser inmediatamente convalidadas por el Consejo Nacional (Cámara de Diputados) convocado por el Poder Ejecutivo y no podían alterar normas constitucionales, crear tributos, enajenar patrimonio estatal o modificar normas laborales, de seguridad social o relativas al derecho de asociación (Ibid.).

Posteriormente, la Ley No. 100 de Italia de 1926 preveía medidas muy similares a los decretos de urgencia, denominándolas «disposiciones con fuerza de ley». Por su parte, la reforma constitucional polaca de 1926 empleaba la expresión «reglamentos con fuerza de ley», permitiéndolos siempre y cuando existiera un interés estatal impostergable y en receso del Congreso (Art. $44^{\circ}$ ) . Poco después, la Constitución de Lituania de 1928 otorgó al Poder Ejecutivo la facultad de "dictar leyes», también durante la suspensión de funciones de la Dieta (Parlamento). Todas estas normas no restringían la competencia de tales disposiciones extraordinarias a determinadas materias (Sagüés, 1985: 20-21).

De otro lado, la Constitución española de la Segunda República (1931) permitía la emisión de decretos «sobre materias reservadas a las Cortes» (Parlamento), llamándolos «decretos-leyes» (arts. 62 y $80^{\circ}$ ), nombre que conservan en la actual Carta Magna de 1978. Estas normas debían dictarse cuando estuvieran en receso las cortes, por urgente necesidad nacional y regirían transitoriamente hasta que las cortes puedan regular sus materias de manera permanente (Planas Silva, 1993: 134).

Por su parte, la Constitución italiana de 1947 reconoce las «ordenanzas de necesidad» con forma de decreto-ley, como potestad normativa del Poder Ejecutivo para casos de necesidad y urgencia, debiendo ser convalidadas inmediatamente por el Parlamento bajo condición resolutoria con efectos retroactivos (Art. $77^{\circ}$ ) (Eguiguren Praeli, 1987: 4271 
La Ley Fundamental de Bonn (1949) y la Constitución francesa de la Quinta República (1958) no contemplaban, en rigor, la institución de los decretos de urgencia. La primera preveía «decretos con fuerza de ley» sólo para regular la situación de refugiados y expulsados (Dromi, 1983: 344). La segunda consagra «decretos-leyes» para que el Presidente de la República ejerza poderes excepcionales durante una suerte de "dictadura constitucional», que ya tenían antecedentes en la Tercera y Cuarta Repúblicas (García-Pelayo, 1984: 506).

Actualmente, la Constitución española de 1978 contempla, como hemos adelantado, la figura de los «decretos-leyes» o «disposiciones legislativas provisionales». Estos deben emitirse cuando hayan situaciones de extraordinaria y urgente necesidad, ser convalidados por el Congreso y no podrán alterar el funcionamiento de las instituciones estatales básicas, los derechos fundamentales de las personas, el régimen de las comunidades autónomas ni los derechos electorales (Santoalalla, 1983: 339-340).

Merece particular mención el texto inspirador de nuestra Carta Magna de 1979, que fue la Constitución venezolana de 1961 al establecer como atribución del Presidente de la República «...dictar medidas extraordinarias en materia económica y financiera, cuando así lo requiera el interés público y haya sido autorizado para ello por ley especial» (Art. 190º) (Cárdenas Quirós, 1987: 40). Aunque este es un antecedente de las "medidas extraordinarias", figura distinta a los decretos de urgencia.

Muchas otras constituciones regulan la institución de los decretos de urgencia, como la de Bulgaria de 1971 (Art. 94%), la de Grecia de 1975

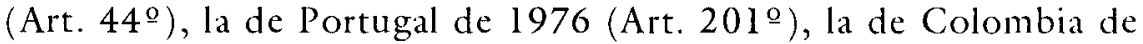
1886 (Art. $122^{\circ}$ ), la de Honduras de 1982 (Art. 245ㅇ), la de Nicaragua de 1987 (Art. 149ㅇ) y la de Brasil de 1988 (Art. 62º) (Ibid.).

Como puede apreciarse, la mayoría de las constituciones enunciadas contemplaron los decretos de urgencia o decretos-leyes como una potestad normativa del Poder Ejecutivo durante el receso del Congreso, les otorgaron fuerza de ley para modificar o suspender transitoriamente leyes, siempre que exista una situación de emergencia nacional o urgente necesidad, y debían ser convalidados posteriormente por el Congreso. Además, la competencia de estas disposiciones extraordinarias no estaba limitada a determinadas materias, salvo en algunas cartas como la española de 1978.

En cuanto al hecho que los decretos de urgencia o decretos-leyes deben ser emitidos durante el receso del Congreso, existen algunas constituciones que los permiten inclusive durante el desarrollo de legislaturas parlamentarias, como la de Italia (Art. $7^{\circ}$ ) y la de Brasil (Art. $62^{\circ}$ ). 


\section{En el Derecho nacional}

La Constitución Política de 1933 no contenía la figura de los decretos de urgencia (De la Puente y Lavalle, 1990: 10). Sin embargo, el gobierno podía emitir algunas disposiciones similares. Estaba facultado para establecer limitaciones a las libertades de comercio e industria (Art. 40) o medidas tendientes a preservar el abaratamiento de las subsistencias (Art. $49^{\circ}$ ), siempre que mediaran situaciones excepcionales calificadas como de «seguridad o necesidad pública» en un caso, y de «circunstancias extraordinarias de necesidad social» en el otro (Eguiguren Praeli, 1987: 435).

Estas disposiciones, que eran transcripciones casi literales de los artículos $45^{\circ}$ y $57^{\circ}$ de la Constitución de 1920 , mas bien aparecen como antecedentes de las «medidas transitorias de carácter extraordinario» del artículo $132^{\circ}$ de la Constitución de 1979 (Planas Silva, 1993: 142), sobre las que trataremos más adelante.

Posteriormente, se dictaron diversas normas infraconstitucionales que plasmaron "medidas extraordinarias". Así, la Ley No. 5085 ( 18 de abril de 1925) estableció el monopolio de la industria y el comercio de fósforos y similares al Poder Ejecutivo a dictar las disposiciones complementarias que requiera la ejecución de la ley, dando cuenta al Congreso del uso que haga de esta autorización. La Ley No. 6566 (12 de marzo de 1929) autorizó al Poder Ejecutivo para adoptar medidas con el objeto de reorganizar el servicio de aduanas.

La Ley No. 7837 (11 de octubre de 1933) permitió al Poder Ejecutivo tomar diversas medidas tributarias con el objeto de recaudar fondos para la instalación y el sostenimiento de fábricas de materiales de guerra (con ocasión de la guerra con Colombia). La Ley No. 8951 (3 de setiembre de 1939) estableció limitaciones a las libertades de comercio e industria mientras exista el estado de guerra. La Ley No. 9098 (9 de mayo de 1940) autorizó al Poder Ejecutivo a dictar medidas mientras dure el conflicto europeo, para facilitar la colocación de nuestros productos de exportación en el extranjero (Ibid.: 142-143).

La Ley No. 9099 (9 de mayo de 1940) permitió al Poder Ejecutivo efectuar, durante el receso del Congreso, operaciones de crédito para cancelar o consolidar las deudas públicas, debiendo destinar los recursos obtenidos a obras públicas. La Ley No. 9161 ( 5 de setiembre de 1940) otorgó fuerza de ley a un decreto supremo que autorizó al Banco Central Hipotecario del Perú a conceder préstamos destinados a reparar inmuebles dañados o destruídos por el terremoto del 24 de mayo de 1940. La Ley No. 9577 (12 de marzo de 1942) autorizó al Poder Eje- 
cutivo a dictar, mientras dure la guerra de los Estados Unidos, las disposiciones necesarias sobre cuentas y operaciones bancarias (Ibid.).

Finalmente, la Ley No. 17044, dictada el 20 de junio de 1968, siendo Ministro de Hacienda el doctor Manuel Ulloa Elías, dispuso que, ante la grave situación económica que padecía el país, el Congreso (dominado por la coalición de oposición APRA-UNO) autorizaba al gobierno a dictar medidas de carácter extraordinario para dar solución al desequilibrio estructural de las finanzas públicas, fortalecer la balanza de pagos y fomentar el desarrollo integral de la economía. Estas medidas se dictarían como decretos supremos con el voto aprobatorio del Consejo de Ministros y, con cargo de dar cuenta en cada caso al Congreso (Eguiguren Praeli, 1990: 31).

$\mathrm{Al}$ amparo de esta autorización, se dictaron numerosos decretos supremos, entre ellos los DD.SS. Nos. 287-68-HC y 297-68-HC, que modificaron y derogaron leyes formales expedidas por el Congreso (De la Puente y Lavalle, 1990: 10).

Como puede apreciarse, las medidas extraordinarias en nuestro país han sido empleadas para regular transitoriamente acontecimientos que configuraban una urgente necesidad nacional, debían ser previamente autorizadas por el Congreso vía ley (no configuran legislación delegada por ser temporales), se emitían cuando éste se encontraba en funciones o en receso indistintamente y, en algunos casos, se exigió que el Poder Ejecutivo «diera cuenta» al Congreso de las mismas.

\section{Regulación en la Constitución de 1979}

\section{Debate preliminar en la Asamblea Constituyente}

El Anteproyecto de Carta Magna presentado por el Partido Popular Cristiano (PPC) a la Asamblea Constituyente instalada en 1978, proponía la incorporación al texto constitucional de los decretos de urgencia, en base a la ponencia sustentada por el doctor Roberto Ramírez del Villar, hasta en cuatro normas (Rubio Correa y Bernales Ballesteros, 1988: 242 y ss.):

a) Durante el receso del Congreso, el presidente de la República podría dictar decretos-leyes en caso de urgencia, con la aprobación del Consejo de ministros y de la Comisión Permanente. El Anteproyecto distinguía esta potestad normativa de la emisión, también por parte del Poder Ejecutivo, de «decretos con fuerza de ley», para los que se exige 
la previa delegación de facultades legislativas del Congreso (antecedente de los decretos legislativos).

b) La Comisión Permanente del Congreso podría autorizar al presidente de la República a dictar decretos-leyes en caso de urgencia, con cargo de dar cuenta al Congreso dentro de los 15 días posteriores a su instalación.

c) Los decretos-leyes que dictaría el presidente de la República serían provisionales y no afectarían el ordenamiento de las instituciones estatales, los derechos y libertades fundamentales ni el régimen de los gobiernos regionales y locales (lo cual denota la clara influencia de la Constitución española de 1978 en la propuesta).

d) Los decretos-leyes de urgencia deberían ser sometidos a debate dentro de los treinta días siguientes a su publicación, para que las cámaras se pronuncien sobre su convalidación.

Curiosamente, de manera simultánea a la propuesta de los «decretosleyes» se planteaba, como una atribución presidencial, la emisión de «medidas extraordinarias» en materia económica y financicra cuando así lo requiriese el interés nacional, previo informe del "Consejo Económico y Social» y con cargo de dar cuenta al Congreso.

Otro Anteproyecto, esta vez presentado por el Partido Socialista Revolucionario (PSR), también contemplaba la figura de los «decretos-leyes» expedidos por el gobierno básicamente para situaciones de graves dificultades en la aplicación de los programas económicos y sociales, así como en circunstancias de emergencia nacional, en materias sobre las que existía reserva legal. Se reiteró la ratificación por el Congreso de los decretos-leyes y sí se exigía, a diferencia de la propuesta del PPC, la previa delegación de facultades legislativas para su emisión (por un período que no debía exceder de sesenta días) (Ibid.: 315 y ss.). Esto último confundía los decretos de urgencia con los futuros decretos legislativos.

En base a estos aportes, el texto original de la ponencia de la Comisión Especial de Poderes del Estado (Comisión 5) contemplaba a los decretos de urgencia como potestad del gobierno previa autorización de la Comisión Permanente del Congreso (que funcionaría en receso de éste), para casos extraordinarios, con los límites propuestos por el PPC, sujetos a revisión por el Congreso y claramente diferenciados de los decretos legislativos. Paralelamente, las «medidas extraordinarias» fueron recogidas también en esta ponencia, en términos casi idénticos a la propuesta del PPC (Planas Silva, 1993: 139-140).

Posteriormente, en sesión del 23 de mayo de 1979, la Comisión Principal revisó el título en torno a la Estructura del Estado. A propues- 
ta del constituyente Enrique Chirinos Soto (PAP) se suprimió la atribución de la Comisión Permanente de autorizar la emisión de decretos de urgencia. Después, con el apoyo del constituyente Roger Cáceres Velásquez (FNTC), propuso la eliminación de los decretos de urgencia por considerar que reforzaban en exceso las facultades normativas del presidente de la República, siendo aprobada esta moción por la Comisión Principal (Asamblea Constituyente, 1979: 473-477).

Curiosamente, las «medidas extraordinarias» fueron aprobadas casi inadvertidamente, sin sufrir modificación la propuesta de la Comisión Especial de Poderes del Estado, resultando el tenor del artículo 211 , inciso 20 de la Carta de 1979 (Ibid.: 187).

De manera que, queda claro que los constituyentes conocieron la institución de los decretos de urgencia, discutieron su incorporación al texto constitucional y, finalmente, no los consideraron, en total consciencia de su decisión (Planas Silva, 1993: 140).

\section{Consagración de las medidas extraordinarias}

Finalmente, el texto constitucional consagró la siguiente redacción en el artículo $211^{\circ}$, inciso 20: «Son atribuciones y obligaciones del Presidente de la República... Administrar la Hacienda Pública; negociar los empréstitos, y dictar medidas extraordinarias en materia económica y financiera, cuando así lo requiera el interés nacional y con cargo de dar cuenta al Congreso».

Esta norma recogió, en principio, una figura hasta entonces desconocida en los textos constitucionales a nivel del Derecho comparado: la de las medidas extraordinarias. Como vimos anteriormente, desde los primeros años del presente siglo, las cartas magnas plasmaron la institución de los decretos de urgencia, pero no las medidas extraordinarias, salvo el antecedente de la Constitución de Venezuela de 1961. Sin embargo, la consagración constitucional de las mismas no responde a las características que poseen en la legislación comparada y nacional precedente, como veremos posteriormente, lo cual pone en tela de juicio si realmente estábamos ante auténticas medidas extraordinarias.

En todo caso es importante resaltar que el empleo del término «medidas» no es casual, pues denota su carácter intrínsecamente temporal, requiriendo de la ulterior convalidación del Parlamento para convertirse en ley (Biscaretti Di Rufia, 1973: 492-499).

Veamos, en primer lugar, si responden a las características de los decretos de urgencia. Estos se emiten sobre todo durante el receso del 
Congreso, mientras que las medidas extraordinarias de nuestra anterior Carta Magna no tienen una precisión al respecto, por lo cual se podrían emitir indistintamente estando en funciones o no el Parlamento. Los decretos de urgencia tienen expresamente atribuida la "fuerza de ley", no nuestras medidas extraordinarias. Se establece claramente la transitoriedad de los decretos de urgencia, no de nuestras medidas extraordinarias.

Se exige la convalidación posterior del Congreso respecto de los decretos de urgencia, mientras que sólo se exige el «rendir cuenta» al mismo de nuestras medidas extraordinarias. Los decretos de urgencia no tienen limitaciones en cuanto a su materia competencial, pero nuestras medidas extraordinarias sí, debiendo circunscribirse a la materia económica-financiera.

En común sólo tienen dos aspectos. Tanto los decretos de urgencia como nuestras medidas extraordinarias están consagradas en textos constitucionales como potestad normativa del Poder Ejecutivo y responden a situaciones de urgente necesidad nacional.

Ahora bien, en cuanto a su compatibilidad con las pautas típicas de las medidas extraordinarias, éstas normalmente han provenido de una delegación de facultades legislativas por el Congreso, a través de una ley autoritativa, mientras que las medidas de nuestra Carta de 1979 tienen origen directamente en ella. Las medidas extraordinarias comunes tienen una naturaleza intrínsecamente temporal, aspecto no contemplado en la Constitución anterior.

Sólo coinciden en tres aspectos con las medidas extraordinarias comunes: responden a una urgente necesidad nacional, pueden ser emitidas mientras el Parlamento esté en funciones y sólo se debe «dar cuenta» de ellas al mismo, no exigiéndose su convalidación posterior.

Como puede apreciarse, las medidas extraordinarias previstas en la Carta de 1979 no responden totalmente a la naturaleza ni de los decretos de urgencia ni de las medidas extraordinarias comunes. Aún así, es imprescindible precisar su naturaleza jurídica.

Numerosas posiciones doctrinales sostienen que las medidas extraordinarias de la Constitución anterior eran decretos de urgencia (Cárdenas Quirós, 1987: 40; Pacheco Barandiarán, 1987: 50; Eguiguren Praeli, 1987: 437; García Belaunde, 1989: 29; De la Puente y Lavalle, 1990: 13). Otras posturas no menos respetables, aunque minoritarias, sostienen que se trataron de auténticas medidas extraordinarias (Bernales Ballesteros, 1989: 151; Planas Silva, 1993: 144).

Particularmente, consideramos que las medidas extraordinarias de nuestra anterior Carta Magna fueron un híbrido entre los decretos de 
urgencia y las medidas extraordinarias comunes resultando, en todo caso, una forma especial de éstas. Después de todo, debemos recordar que la propuesta de los decretos de urgencia o decretos-leyes, planteada por el PPC en los debates de la Asamblea Constituyente, fue expresamente desestimada, permaneciendo incólume la propuesta de las medidas extraordinarias.

Si se hubiera respetado la exigencia inicialmente prevista de la autorización previa por el «Consejo Económico y Social» (proyecto del PPC) o, de la ley autoritativa especial (Constitución venezolana de 1961), seguramente habrían menos dudas de su identidad con las medidas extraordinarias comunes.

\section{Efectos y requisitos de las medidas extraordinarias}

\subsection{Rango jerárquico}

La Constitución de 1979 no previó expresamente un determinado nivel normativo para las medidas extraordinarias. En esa medida, se elaboraron dos posiciones doctrinales, con respaldo en nuestra jurisprudencia. La primera de ellas sostuvo que las medidas extraordinarias eran normas de nivel secundario o tenían rango de simples decretos supremos, mientras que la segunda argumentó que tales medidas tenían nivel primario o rango de ley. Analicemos brevemente cada una de las dos posturas.

Como vimos anteriormente, durante el debate surgido en la Asamblea Constituyente no se consideró finalmente la incorporación de los decretos de urgencia o decretos-leyes, propuesta por el PPC. En ella se planteaba inequívocamente que dichas disposiciones tengan fuerza de ley, para modificar o suspender transitoriamente normas de nivel primario. En ese sentido, se ha sostenido que, en tanto las medidas extraordinarias son distintas a los decretos de urgencia o decretos-leyes, no pueden tener rango de ley, sino simplemente nivel secundario o reglamentario (Bernales Ballesteros, 1989: 151).

Otra de las razones esgrimidas en favor de esta posición consiste en afirmar que, nuestra anterior Carta Magna señalaba expresa y taxativamente qué normas tenían rango o fuerza de ley, entre las que no figuraban las medidas extraordinarias (Ibid.). Así, teníamos a las leyes propiamente dichas y las resoluciones legislativas emanadas del Parlamento (Art. $186^{\circ}$, inc. 1), los tratados internacionales (Art. $101^{\circ}$ ), los decretos legislativos (Arts. $188^{\circ}$ y $211^{\circ}$, inc. 10 ), los reglamentos del Congreso y de cada Cámara (Art. 177²), el convenio colectivo (Art. 
$\left.54^{\circ}\right)$ y, normas regionales de carácter general y ordenanzas municipales (Art. $298^{\circ}$, inc. 1 ).

En esa medida, se ha afirmado que las medidas extraordinarias no pueden alterar o derogar normas de rango legal (Pareja Paz Soldán, 1980: 322; Chirinos Soto, 1984: 231). Otros, menos categóricamente pero incurriendo en una contradicción, sostienen que dichas medidas no tienen fuerza de ley pero pueden suspender normas de nivel primario (Aramburú Menchaca, 1990: 24).

Esta posición ha encontrado algún sustento jurisprudencial. Ante una acción de inconstitucionalidad interpuesta por veinte senadores contra el Decreto Supremo No. 057-90-TR, emitido al amparo del artículo $211^{\circ}$, inciso 20 de la anterior Constitución, el Tribunal de Garantías Constitucionales declaró inadmisible la demanda. El sustento argumentado consistía en que, en tanto las medidas extraordinarias no se encontraban dentro de las normas impugnables vía acción de inconstitucionalidad (Art. 298ㅇ), no podían ser cuestionadas por ésta.

En algunos votos singulares de los miembros del TGC (DiezCanseco, Pelayo Samanamud), se puede apreciar claramente que consideraban impugnables las medidas extraordinarias vía la acción popular, lo cual les otorga tácitamente un rango secundario o reglamentario (Art. $\left.295^{\circ}\right)$.

Por otro lado, hay quienes piensan que si la potestad de emitir decretos supremos ordinarios se encuentra prevista en una norma distinta (Art. $21^{\circ}$, inc. 11) a la de las medidas extraordinarias, éstas no pueden tener el mismo nivel jerárquico, pudiendo configurar disposiciones con fuerza de ley. Resultaría redundante e innecesario que las medidas extraordinarias estén previstas en una norma distinta a la de los decretos supremos ordinarios, si tuvieran rango secundario o reglamentario (Eguiguren Praeli, 1987: 443-444; De La Puente y Lavalle, 1990: 13).

Además, los requisitos exigidos a las medidas extraordinarias son distintos a los planteados respecto de los decretos supremos ordinarios. Aqucllas deben ser precisamente extraordinarias en tanto responden a situaciones de urgente necesidad nacional, sólo pueden regular materia económico-financiera y el Poder Ejecutivo debe rendir cuenta de su utilización al Congreso. Ninguno de estos requisitos es exigido a los decretos supremos ordinarios, los que sólo deben regular las leyes sin transgredirlas ni desnaturalizarlas (Eguiguren Praeli, 1987: 444; Cárdenas Quirós, 1987: 39; García Belaunde, 1989: 29).

También se ha sostenido que, ante la exigencia de la intervención del Congreso para la emisión de normas con fuerza de ley, ella se cumple 
respecto de las medidas extraordinarias. El régimen de división de poderes que inspiraba la Constitución de 1979 establecía, en principio, que toda norma de rango o fuerza legal fuera emitida o delegada por el Parlamento. Sin embargo, no se especificaba que este rol del Congreso debía ser necesariamente previo a la emisión normativa, pudiendo ser posterior. Así, el "dar cuenta» al Parlamento de las medidas extraordinarias debía entenderse como la exigencia de una convalidación posterior del mismo respecto de éstas (De la Puente y Lavalle, 1990: 14; Marienhoff, 1970: 254; Alessi, 1970: 29).

Particularmente, compartimos esta segunda posición: las medidas extraordinarias tienen fuerza de ley, pues pueden modificar o suspender (no derogar) transitoriamente normas de nivel primario. Adicionalmente, existen algunas razones de teoría general que fundamentan esta afirmación.

El estado de urgente necesidad requiere inmediata regulación, no pudiendo esperar al trámite ordinario de la emisión de una ley en sentido formal o de la delegación de facultades legislativas para dictar otras normas de nivel primario. Por ello, resulta imprescindible emitir medidas extraordinarias (Dromi, 1973: 356) que tengan potencia igual a la de la ley (Diez, 1963: 446), en tanto ésta no debe ser obstáculo para implantar rápidamente la nueva regulación (Alzaga Villaamil, 1978: 558).

A nivel jurisprudencial, la Corte Suprema de la República, contrariamente a lo señalado por el TGC, ha señalado reiteradamente que las medidas extraordinarias tienen fuerza de ley, como en el Expediente No. 1613-89-LAMBAYEQUE, que contenía un juicio de desahucio en el que se discutió la validez del Decreto Supremo No. 268-87-EF, emitido al amparo del artículo $211^{\circ}$, inciso 20 de la Carta de 1979, que estableció una prórroga de los contratos de alquiler sobre los predios sujetos a la Ley del Inquilinato.

Como puede apreciarse, el TGC y la Corte Suprema de la República tenían criterios encontrados respecto al rango jerárquico de las medidas extraordinarias. En el ejercicio del control concentrado de la constitucionalidad de las normas, el TGC apareció como uno de los intérpretes auténticos de la Carta Magna (Fernández Segado, 1984: 234), con lo cual deberíamos haber asumido su interpretación y considerar que las medidas extraordinarias no tienen fuerza de ley. Pero, en el ejercicio del control difuso de la constitucionalidad de las normas, la Corte Suprema de la República apareció como otro de los intérpretes auténticos de la Constitución (Quiroga León, 1989: 40). En esa medida, tenemos dos posiciones jurisprudenciales igualmente válidas, cada una de las cuales sigue una de las dos corrientes doctrinales enunciadas. 


\subsection{Justificación, competencia y control}

En cuanto a la justificación de las medidas extraordinarias, éstas debían dictarse cuando exista una urgente necesidad nacional, que no es de carácter genérico sino específico, agudo, de súbita aparición y de impostergable atención dada su anormalidad y la eventual gravedad de sus consecuencias (Marienhoff, 1970: 230). Es importante que la situación configurada sea imprevisible y no pueda ser afrontada de otra manera, como en el caso de terremotos, invasiones, huracanes, emergencias económicas, etc. Para regular las situaciones normales, el Poder Ejecutivo cuenta con los decretos supremos ordinarios (García Belaunde, 1989: 29).

En la jurisprudencia constitucional comparada podemos encontrar una acertada precisión del "presupuesto de hecho habilitante» (Torres del Moral, 1986: 145), es decir, de la excepcional y urgente necesidad nacional (si bien pensada para los decretos de urgencia o decretos-leyes, que tienen este rasgo en común con las medidas extraordinarias).

El Tribunal Constitucional español ha señalado en dos sentencias $(6 / 1983$ y $111 / 1983)$ que la extraordinaria y urgente necesidad no debe entenderse en el sentido extremo de una amenaza para la nación o el sistema constitucional, dado que para tales casos la Carta Magna ha previsto los mecanismos del régimen de excepción. En esa medida, debe pensarse mas bien en situaciones en las que se configura una necesidad «relativa» respecto a las situaciones concretas en que se encuentran los objetivos de la actuación gubernamental los cuales, por razones difíciles de preveer, requieren en alguna ocasión una acción normativa inmediata, en un plazo más breve que el requerido para la producción parlamentaria de una ley pues, de lo contrario, se perdería eficacia en la regulación de tales situaciones (Cortes Generales, 1983: 34).

Esto supone, ciertamente, una concentración extraordinaria de poderes en el gobierno, justificada por la urgente necesidad nacional (Lamarque, cit. en Linares Quintana, 1970: 502; Camus, 1965: 25).

En cuanto a la competencia de las medidas extraordinarias, es decir, las materias que pueden ser reguladas por estos instrumentos normativos, el texto constitucional los limitaba a asuntos económico-financieros. Aquí encontramos dos problemas concretos: determinar qué aspectos específicos se encuentran incluídos dentro de lo económico y financiero, y si dichos aspectos pueden ser aquellos sometidos a reserva de ley para su regulación (Eguiguren Praeli, 1987: 446).

En lo que respecta a qué debemos entender por materia económica y financiera, debía aplicarse un criterio restrictivo en la selección de los as- 
pectos que cumplen con dicha condición. Lo económico y financiero debe ser lo principal en estos y no lo accesorio porque, llevado este argumento hasta sus últimas consecuencias, todo podría ser económico-financiero, con lo cual podríamos afectar una serie de derechos fundamentales. Así, debía circunscribirse la competencia de las medidas extraordinarias a los aspectos regulados en la parte económica de la Carta Magna anterior, no comprendiendo las partes dogmática y orgánica (García Belaunde, 1989: 29-30).

Al ser necesario que las materias regulables por las medidas extraordinarias tengan incidencia directa en lo económico y financiero, resultarían comprendidas los aspectos tributarios, presupuestales, aduaneros, los incentivos promocionales, empréstitos, operaciones financieras y crediticias, etc. (Pacheco Barandiarán, 1987: 52; Eguiguren Praeli, 1987: 447).

En lo que respecta a si las medidas extraordinarias pueden regular materias sobre las que existe reserva legal, la respuesta viene adelantada implícitamente. En tanto tales medidas gozan de fuerza de ley, ello es posible. Solo que para evitar posibles abusos en el empleo de esta figura, es importante verificar que tales normas duren solamente mientras dure la circunstancia extraordinaria habilitante y que sean ratificadas por el Congreso (Ibid.). Además, debía respetarse la reserva legal respecto de temas propios de las leyes orgánicas, pues la Constitución anterior exigía para su aprobación mayoría calificada (García Belaunde, 1989: 32).

Por último, en cuanto al control de las medidas extraordinarias, la Constitución de 1979 establecía que el Poder Ejecutivo debía emitirlas "con cargo de dar cuenta al Congreso". Pero omitió precisar en qué consiste el procedimiento de fiscalización y cuáles serían los efectos y alcances derivados de la misma. Este procedimiento resulta imprescindible, pues el Gobierno ejerce una potestad normativa desequilibrante de la división de poderes estatales con tales medidas, que se plasma en normas jurídicas con fuerza de ley capaces, por ende, de suspender o modificar transitoriamente normas de nivel primario. De lo que se trata es de revisar el cumplimiento de los requisitos exigidos a las medidas extraordinarias para su validez, convalidándolos o anulándolos (Eguiguren Praeli, 1987: 450).

\section{Las medidas del artículo $132^{\circ}$}

En el Título III (Régimen Económico), Capítulo IV (De la Empresa), artículo $132^{\circ}$ de la Constitución anterior, se contemplan medidas apa- 
rentemente idénticas a las previstas en el artículo $21^{\circ} \stackrel{\circ}{ }$, inciso 20 , señalándose textualmente que: "En situaciones de crisis grave o de emergencia, el Estado puede intervenir la actividad económica con medidas transitorias de carácter extraordinario".

Como señalamos anteriormente, esta norma tuvo sus antecedentes en los artículos $40^{\circ}$ y $49^{\circ}$ de la Constitución de 1933 , que se referían a la posibilidad de establecer limitaciones a las libertades de comercio, industria y contratación y a la empresa misma (Eguiguren Praeli, 1990: 41).

Las medidas extraordinarias del artículo $132^{\circ}$ de la Carta de 1979 tenían por finalidad garantizar el desarrollo de los principios esenciales del régimen económico en ella previsto, cuando existían situaciones de real crisis y emergencia que afectasen la actividad económica y empresarial como, por ejemplo, acaparamiento, especulación, monopolio, bruscas alzas o caídas de precios, etc. Mediante tales instrumentos normativos se buscaba imponer obligaciones, restricciones y prohibiciones temporales sobre las libertades de comercio, industria y contratación (Ibid.: 43-44).

En tanto la posibilidad de emitir estas medidas extraordinarias era una facultad atribuida genéricamente al Estado, podrían tener la forma de leyes del Congreso o decretos supremos del Poder Ejecutivo (Ibid.: 41). En este segundo caso, dado que la Constitución anterior no exigía que se de cuenta de tales medidas al Congreso, a diferencia de las medidas del artículo $211 \circ$, inciso 20 , debían tratarse de decretos supremos ordinarios, sin fuerza de ley (Eguiguren Praeli, 1994: 187).

\section{La Ley No. 25397}

Ante el empleo exagerado y abusivo que de las medidas extraordinarias se hizo casi desde el inicio de la presente etapa democrática (las que empezaron la discusión antes expuesta fueron los DD.SS. Nos. 100, 175,179 y 198-83-EFC, a mediados de 1983), y de los efectos perniciosos que venían causando, resultó importante abordar la regulación de diversos aspectos: establecer un tipo especial de norma para expedir e identificar las medidas extraordinarias, para así poder distinguirlas de los decretos supremos ordinarios; precisar que tales medidas tenían fuerza de ley y eran necesariamente temporales; determinar en qué consistía su proceso de convalidación ulterior por el Congreso; regular qué se debía entender por materias económico-financieras; y, especificar qué tipo de control jurisdiccional de constitucionalidad les correspondía (Eguiguren Praeli, 1990: 39-40). 
Varios años después de promulgada la Constitución de 1979 , el Congreso dictó la Ley No. 25397 (9 de febrero de 1992), Ley de Control Parlamentario sobre los actos normativos del Presidente de la República, que tenía como principal objetivo darle contenido al «dar cuenta al Congreso» previsto en el artículo $211^{\circ}$, inciso 20 de la anterior Carta Magna (Planas Silva, 1993: 150). Adicionalmente, esta Ley reguló diversos aspectos relativos a las medidas extraordinarias.

En principio, dio una denominación especial a las medidas extraordinarias, los «decretos supremos extraordinarios» (DSE); estableció su carácter temporal por el tiempo que la norma indicara, no pudiendo superar los seis meses de duración; y, declaró expresamente que tales medidas podían dejar en suspenso normas de nivel primario (Eguiguren Praeli, 1994: 185).

Además, precisó los aspectos que podían ser materia económica y financiera: la reestructuración de los gastos del Gobierno Central y las empresas del Estado, establecidos en la Ley Anual de Presupuesto; la modificación o suspensión temporal de tributos; la realización de operaciones de emergencia en materia de endeudamiento externo e interno, para proveer recursos financieros destinados a atender necesidades públicas impostergables; y la intervención de la actividad económica, de conformidad con el artículo $132^{\circ}$ de la Constitución de 1979 (Art. $4^{\circ}$ ).

Es importante destacar que, tanto las medidas extraordinarias del artículo $211^{\circ}$, inciso 20, como las del artículo $132^{\circ}$ de la Carta Magna anterior, fueron fusionadas en la figura de los DSE. Como hemos sostenido, cuando tales medidas debían provenir del Poder Ejecutivo, sólo las primeras podrían tener fuerza de ley, más no las segundas. En esa medida, la equivalencia entre ambas clases de medidas extraordinarias resultó poco técnica. Probablemente, el propósito del legislador consistió en intentar evitar que, a través de la figura del artículo $132^{\circ}$ de la Constitución de 1979, se genere una nueva brecha para el empleo excesivo y abusivo de las medidas extraordinarias (Ibid.: 187).

Por otro lado, la Ley No. 25397 sostuvo que el control jurisdiccional de los «decretos supremos extraordinarios» (DSE) podría ejercerse a través de la acción popular (Art. $12^{\circ}$ ) que, como se sabe, estaba destinada a cuestionar normas de nivel secundario o reglamentario (Art. $295^{\circ}$ Const.). Resulta contradictorio que, por un lado, se les reconozca a los DSE fuerza de ley y, por otro, se les asigne una vía de control de constitucionalidad prevista para los decretos supremos ordinarios.

Por último, reguló un procedimiento de control parlamentario de los DSE, convalidándolos por "silencio positivo". A las veinticuatro horas de publicado el DSE, el presidente de la República debe dar cuenta de 
su emisión por escrito al presidente del Congreso o de la Comisión Permanente, acompañando copia del DSE (Art. 9ํ). Este es remitido a las comisiones de Constitución y Leyes Orgánicas de ambas cámaras, para su estudio y emisión del dictamen en el plazo de quince días útiles (Art. $10^{\circ}$ ). Sólo se emite dictamen si es desfavorable al DSE, y si el Congreso o la Comisión Permanente coinciden con el mismo se aprueba un acuerdo que, una vez publicado en «El Peruano», deroga el DSE (Art. 11ํ).

\section{Regularización en la Constitución 1993}

\section{Consagración de los decretos de urgencia}

El artículo $118^{\circ}$, inciso 19 de la actual Carta Magna precisa lo siguiente: "Corresponde al Presidente de la República... dictar medidas extraordinarias, mediante decretos de urgencia con fuerza de ley, en materia económica y financiera, cuando así lo requiere el interés nacional y con cargo de dar cuenta al Congreso. El Congreso puede modificar o derogar los referidos decretos de urgencia».

Siempre como potestades del Poder Ejecutivo, se regulan por separado la administración de la Hacienda Pública y la negociación de los empréstitos, que aparecían junto a la atribución anterior en la Constitución de 1979. Ello, por cierto, implicaba una positivización asistemática, en tanto no existía justificación para mezclar en una misma norma funciones habituales u ordinarias del presidente de la República, con otras de naturaleza claramente excepcional (Eguiguren Praeli, 1987: 437).

Además, se prohíbe expresamente que los decretos de urgencia puedan regular materia tributaria (Art. $74^{\circ}$ ) y se les incluye como norma impugnable, vía la acción de inconstitucionalidad ante el Tribunal Constitucional (Art. 200ㅜ, inc. 4).

Pues bien, la primera modificación que salta a la vista consiste en el cambio de instrumento normativo por el cual se deben canalizar las medidas extraordinarias: se pasa de los decretos supremos a los decretos de urgencia, los cuales tendrán fuerza de ley. Pero es importante resaltar que todavía se sigue hablando de medidas extraordinarias, considerando erróneamente que pueden plasmarse a través de decretos de urgencia. No se asume que doctrinariamente es posible distinguir entre ambas instituciones, de modo tal que se debe optar o por las medidas extraordinarias o por los decretos de urgencia.

En ese sentido, resulta evidente que no estamos ante auténticos decretos de urgencia o decretos-leyes, sino nuevamente ante una noción 
particular e imperfecta de medidas extraordinarias. Los primeros se caracterizan por emitirse durante el receso del Congreso, ser transitorios, poder regular cualquier materia y estar sujetos a convalidación posterior por el Parlamento. Estos aspectos no han sido contemplados en el artículo $118^{\circ}$, inciso 19 de la nueva Carta Magna.

Tampoco llegan a ser medidas extraordinarias comunes, pues éstas también son temporales, responden a una delegación de facultades legislativas y se emiten durante el receso parlamentario.

Sin embargo, la Constitución de 1993 aporta un elemento sumamente importante: zanja la discusión en torno a si la medida extraordinaria tiene o no fuerza de ley. Dice explícitamente y también indirectamente, a través de su vía judicial de impugnación, que tiene fuerza de ley pudiendo suspender normas de nivel primario.

\section{Justificación, competencia y control}

En cuanto al supuesto habilitante para la emisión de las nuevas medidas extraordinarias, se reitera la frase "cuando así lo requiere el interés nacional", que proviene de la Carta Magna anterior. Esta terminología no necesariamente garantiza que sólo se dicten tales medidas cuando lo demande una urgente necesidad nacional, pues resulta demasiado genérica (Eguiguren Praeli, 1994: 189). De otro lado, no se regula su temporalidad, menos aún que deben existir sólo mientras dure la situación extraordinaria que las motivó.

En cuanto a las materias que pueden ser normadas por las medidas extraordinarias, también se reitera la enunciación de lo económico y financiero, sin detallar qué aspectos deben ser comprendidos en esta temática. Sólo se dispone la exclusión de la materia tributaria. Con ello no se contribuye a combatir eficazmente el uso excesivo y abusivo de las medidas extraordinarias, alimentado principalmente por esta imprecisión. Si se trataran de verdaderos decretos de urgencia, como señalamos, no tendrían limitación alguna, estando sí sujetos a un adecuado proceso de convalidación parlamentario ulterior.

En cuanto al control de este poder normativo otorgado al Poder Ejecutivo, se vuelve a plantear el simple «dar cuenta al Congreso", sin precisar en qué consiste. En esa medida, no se contempla un proceso de convalidación parlamentaria ulterior de las disposiciones en mención. Sin embargo, el punto de partida para ello podría ser la última parte del artículo 118, inciso 19: «El Congreso puede modificar o derogar los referidos decretos de urgencia». 
Recientemente ha sido promulgado el Reglamento del Congreso (26 de junio de 1995), en cuyo artículo 91 se reitera el procedimiento de control parlamentario de las medidas extraordinarias, bajo la modalidad de convalidación por «silencio positivo", regulado en la Ley No. 25397. Solo se elimina la alusión a las comisiones de Leyes Orgánicas de ambas cámaras (ahora el Congreso es unicameral) y se opta por derogar una medida extraordinaria inconstitucional mediante ley expresa.

\section{Los decretos de urgencia del artículo $135^{\circ}$}

Ahora bien, en su artículo $134^{\circ}$ la nueva Constitución trata el tema de la disolución del Congreso por censura o negación de confianza a dos consejos de ministros. Y, en el segundo párrafo del artículo $135^{\circ}$ señala que, hasta que se forme el nuevo Congreso, el Poder Ejecutivo legisla mediante decretos de urgencia, de los que da cuenta a la Comisión Permanente para que los examine y los eleve al Congreso, una vez que éste se instale.

Probablemente estos sí sean auténticos decretos de urgencia, en tanto el Congreso si bien no está en receso, no ejerce sus funciones; son normas transitorias sujetas a convalidación parlamentaria posterior; y no tienen limitación alguna en cuanto a las materias a regular. El único elemento con el que no contarían es la justificación para su emisión sólo en una urgente necesidad nacional, aunque podría pensarse que la disolución del Congreso precisamente configura ésta.

De este modo, podríamos afirmar que la regla es que el Poder Ejecutivo dicte medidas extraordinarias bastante peculiares (Art. $118^{\circ}$, inc. 19), y la excepción es que emita auténticos decretos de urgencia sólo para el caso del interregno parlamentario antes descrito.

\section{Conclusiones}

1) En el Derecho Constitucional comparado, los decretos de urgencia o decretos-leyes aparecen como una potestad normativa del Poder Ejecutivo que se ejercita con las siguientes características: durante el receso del Congreso, tienen fuerza de ley por lo que pueden modificar o suspender transitoriamente leyes, responden a una situación de emergencia nacional o urgente necesidad, y deben ser convalidados posteriormente por el Parlamento.

2) En el Derecho nacional y comparado, las medidas extraordinarias 
aparecen como una potestad normativa del Poder Ejecutivo que se ejercita con las siguientes características: requieren autorización previa del Congreso, tienen fuerza de ley, responden a una urgente necesidad nacional, y se exige que el gobierno rinda cuenta al Parlamento de las mismas, que se emiten cuando éste se encuentra o no en receso.

3) En la Asamblea Constituyente se discutió y descartó la inclusión de los decretos de urgencia en el texto de la Carta Magna de 1979. Pero sí se recogió una figura particular de medidas extraordinarias, con fuerza de ley.

4) Las medidas extraordinarias deben regular materias directamente vinculadas con lo económico y financiero y deben ser sometidas a convalidación posterior por el Congreso.

5) Las medidas extraordinarias del artículo $132^{\circ}$ de la Constitución de 1979 regulaban desequilibrios del sistema económico, mediante leyes formales o decretos supremos ordinarios.

6) Los decretos de urgencia de la actual Carta Magna son realmente medidas extraordinarias sumamente peculiares, con fuerza de ley. No pueden regular materia tributaria.

7) Sólo las normas del artículo $135^{\circ}$ de la Constitución de 1993 son auténticos decretos de urgencia, pudiendo emitirse únicamente durante el período que media entre un Congreso disuelto y uno nuevo.

\section{Bibliografia}

Alessi, Renato. Instituciones de Derecho Administratipo. Tomo I. Barce1970 lona, Ed. Tecnos.

Alzaga Villaamil, Oscar. La Constitución española de 1978. Comentario 1978 sistemático. Madrid, Ed. del Foro.

Aramburú Menchaca, Andrés. "Las medidas extraordinarias". En: El 1990 Comercio, Lima, 14 de setiembre.

Asamblea Constituyente de 1979. Diario de Debates de la Comisión Principal, tomo III.

Bernales Ballesteros, Enrique. "El funcionamiento del sistema político 1989 de la Constitución de 1979". En: AA.VV. La Constitución diez años después. Lima, Fund. Naumann. 
Biscaretti Di Ruffia, Paolo. Derecho Constitucional. Madrid, Ed. 1973 Tecnos.

Camus, Geneviere. El Estado de Necesidad en Democracia. París. 1965

Cárdenas Quirós, Carlos. "Los Decretos con Fuerza de Ley". En: 1987 Thémis Revista de Derecho, Segunda Epoca, No. 6. Lima, PUCP, 1987.

Cortes Generales De España. Boletín de Jurisprudencia Constitucional, 1983 No. 23. Madrid, marzo.

Chirinos Soto, Enrique. La nueva Constitución al alcance de todos. Lima, 1984 AFA Editores, 3a. edición.

De la Puente y Lavalle, Manuel. "Las medidas extraordinarias". En: El 1990 Comercio, edición del 3 de setiembre.

Diez, Manuel María. Derecho Administrativo. Tomo I. Buenos Aires, 1963 Ed. Astrea, 1963.

Dromi, Roberto. Instituciones de Derecho Administrativo. Buenos Aires, 1983 Ed. Astrea, 1983.

Eguiguren Praeli, Francisco. "Funciones Legislativas del Poder Ejecuti1987 vo". En: Francisco Eguiguren Praeli. La Constitución Peruana de 1979 y sus problemas de aplicación. Lima, Cultural Cuzco.

Eguiguren Praeli, Francisco. "Las situaciones de emergencia y su trata1990 miento en la Constitución Peruana de 1979". En: Lecturas sobre Temas Constitucionales No. 5. Lima, CAJ.

Eguiguren Praeli, Francisco. "La legislación delegada y los decretos de 1994 urgencia en la Constitución peruana de 1993". En: AA.VV. La Constitución de 1993, análisis y comentarios. Lima, CAJ.

Fernández Segado, Francisco. La Jurisdicción Constitucional en España. 1984 Madrid, Dykinson.

García Belaunde, Domingo. "Funciones legislativas del Ejecutivo mo- 
1989 derno: el caso peruano". En: Lecturas sobre Temas Constitucionales No. 3. Lima, CAJ.

García-Pelayo, Manuel. Derecho Constitucional Comparado. Madrid, 1984 Alianza Universidad.

Linares Quintana, Segundo. Derecho Constitucional e Instituciones Poli1970 ticas. Tomo II. Buenos Aires, Abeledo-Perrot.

Marienhoff, Miguel. Tratado de Derecho Administrativo. Tomo I. Bue1970 nos Aires, Ed. Astrea.

Pacheco Barandiarán, Rosario. "Los Decretos de Urgencia y un vacío 1987 en la Constitución de 1979". En: Thémis, Revista de Derecho, Segunda Epoca, No. 6. Lima, PUCP.

Pareja Paz Soldán, José. Derecho Constitucional peruano y la Constitu1980 ción de 1979. Tomo I. Lima.

Planas Silva, Pedro. "Decreto de urgencia y medidas extraordinarias». 1993 En: Ius et Veritas, Año IV, No. 7. Lima, PUCP, noviembre.

Quiroga León, Aníbal. "El modelo de la Constitución de 1979". En: 1989 AA.VV. La Constitución diez años después. Lima, Fund. Naumann.

Rubio Correa, Marcial y Enrique Bernales Ballesteros. Constitución: 1988 fuentes e interpretación. Lima, Mesa Redonda Editores.

Sagués, Néstor Pedro. "Los decretos de necesidad y urgencia: derecho 1985 comparado y derecho argentino". En: La Ley, Buenos Aires, edición del 15 de noviembre.

Santoalalla, Fernando. Derecho Parlamentario Español. Madrid, Ed. 1983 Civitas.

Torres del Moral, Antonio. Principios de Derecho Constitucional Espa1986 ñol. Madrid, Atomo Ediciones. 